\title{
Linear and whorled nevoid hypermelanosis
}

INSERM

\section{Source}

INSERM. (1999). Orphanet: an online rare disease and orphan drug data base. Linear and whorled nevoid hypermelanosis. ORPHA:79150

A rare hyperpigmentation of the skin disease characterized by the congenital to infantileonset of bilateral, diffuse (occasionally localized), reticulate (swirls and streaks), macular hyperpigmentation following the lines of Blaschko, typically involving the trunk, limbs, head and neck (but sparing palms, soles and mucosa), without preceding inflammation, blistering or atrophy. Occasionally, extracutaneous abnormalities, including autism, seizures, cardiac defects, skeletal abnormalities and developmental delay, may be associated. Histologically, basal and/or suprabasal melanosis, without pigment incontinence, is observed. 